\title{
Milestones and new ventures
}

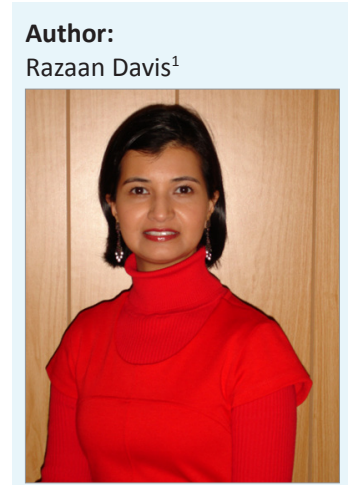

Affiliation:

${ }^{1}$ Faculty of Medicine and Health Sciences, Stellenbosch University, South Africa

Email:

editor@sajr.org.za

Postal address:

Division of Radiodiagnosis, Department of Medical

Imaging and Clinical

Oncology, Tygerberg

Hospital, PO Box 19063

Tygerberg 7505, South Africa

How to cite this article:

Davis R. Milestones and new ventures. S Afr J Rad. 2014;18(1); Art. \#610,

1 page. http://dx.doi/ org.10.4102/sajr.v18i1.610

\section{Copyright:}

(C) 2014. The Authors. Licensee: AOSIS

OpenJournals. This work

is licensed under the

Creative Commons

Attribution License.
We take cognisance of the 50 years since the South African Journal of Radiology (SAJR) first appeared as a supplement of the South African Medical Journal (SAMJ) in April 1963. Although not in continuous print, it nevertheless documented the development of South African radiology, serving as a repository for the mostly unique and always interesting cases.

The SAJR, however, must continue to evolve in order to remain contemporary. I therefore happily announce that the SAJR will now publish exclusively online, with no print copy, except inter alia a copy for the National Archives of South Africa.

This is a considerable step toward making the journal accessible to a broader international audience. African Online Scientific Information Systems (Pty) Ltd (AOSIS) OpenJournals will publish the SAJR online in PDF, html, $\mathrm{xml}$ and ePub format as a rolling publication, its archives accessible to all users. Signing up for 'article alerts/notification' on the SAJR webpage will inform users when a new article is available online.

The SAJR will remain an open access peer-reviewed scholarly journal. The Radiological Society of South Africa (RSSA) has undertaken, at this time, to fully subsidise the publishing cost, which translates to 'no author fees'. The journal meets the criteria of the Department of Higher Education and Training (DoHET) and is therefore accredited and approved by the DoHET for inclusion in the subsidy system. We will continue to provide a continuous professional development (CPD) programme.

The SAJR aims to refine its focus and scope, thereby carving its niche. It is my intention to give South African radiology wider exposure by including a Special Focus Musculoskeletal Issue during the course of this year. The cases presented by the South African Musculoskeletal Imaging Group (SAMSIG) at the first RSSA/SAMSIG Advanced Musculoskeletal Imaging Course at the V \& A Waterfront, Cape Town, 21-23 February 2014, provides this opportunity.

In further contributory efforts to excellence in radiology, and marking the next 50 years of the SAJR, I am delighted to introduce an important series of editorials contributed by the Centre for Evidence-based Health Care and Division of Community Health located at the Faculty of Medicine and Health Sciences, Stellenbosch University. The intent is to encourage appropriate imaging in South Africa by promoting the practice of evidence-based radiology. I hope that you will find this series both enlightening and encouraging. 